EESTI NSV TEADUSTE AKADEEMIA TOIMETISED. VI KÖIDE BIOLOOGILINE SEERIA. 1957. NR. 4

ИЗВЕСТИЯ АКАДЕМИИ НАУК ЭСТОНСКОЙ ССР. ТОМ VI СЕРИЯ ВИОЛОГИЧЕСКАЯ. 1957, 스 4

\title{
KOHALIKU SIRPLUTSERNI LEVIK JA PÖLLUMAJANDUSLIK KASUTAMINE SAAREMAAL
}

\section{LAUR}

Sirp- ehk kollane lutsern (Medicago falcata L.) on looduslikult levinud Pōhja-Eesti ja saarte enamasti kuivematel lubjarikastel rähk-, liiv-, liivsavija saviliivmuldadel, lagendikkudel ja teeservadel $\left[1,2,{ }^{10},{ }^{11}\right]$.

Saartel on suuremad sirplutserni levikualad Orissaare rajoonis Leisi asunduse ümbruses ja Hiiumaa rajoonis Kassari saarel.

Andmeid sirplutserni põllumajandusliku kasutamise kohta Eestis on avaldanud J. Mets $\left[{ }^{3}\right]$, H. Otstavel $\left.{ }^{[4}\right]$, N. Rootsi $\left[{ }^{5}, 6\right]$, R. Toomre $\left.{ }^{[8}\right]$ jt.

Eesti NSV-s on sirplutserni külvatud ja laialdasemalt kasutusele võetud viimastel aastatel Orissaare rajoonis. «Vesse» kolhoosis on teda külvatud 12-15 ha, «Jüriöö» kolhoosis 4 ha, A. S. Puškini nimelises kolhoosis 4 ha, Eesti Maaviljeluse ja Maaparanduse Teadusliku Uurimise Instituudi Karja katsepunktis 4 ha, vähesel määral «Ranniku» ja «Ưhise Jõu» kolhoosis. Varemates sirplutserni kasvatamise katsetes Eestis kasutati teda peamiselt niiteliselt. Viimasel ajal on sirplutserni heade tulemustega kasutatud ka karjamaataimena põuakartlikel rähkmuldadel (peamiselt Orissaare rajoonis).

\section{Sirplutserni kirjeldus ja bioloogia}

Sirplutsern on mitmeaastane taim liblikõieliste sugukonnast. Oma morfoloogilistelt omadustelt on ta üsna lähedane harilikule lutsernile, erinedes sellest vaid õite kollase värvuse, väiksemate ja kitsamate lehtede ning kauna ehituse poolest [ $\left.{ }^{7}\right]$. Kohaliku sirplutserni vormid on juurevõrselised ja erinevad selle tõttu põhiliselt nii harilikust lutsernist kui ka «Dedinovi kolla. sest» [ ${ }^{9}$. Eesti Maaviljeluse ja Maaparanduse Teadusliku Uurimise Instituudi Kuusiku katsebaasi teadusliku töötaja L. Kõrgase arvamusel moodustab ka «Dedinovi kollane» juurevõrseid.

Kohalik sirplutsern on meie oludega hästi kohanenud [ ${ }^{6}$; ta on külmakindlam ja vähenõudlikum kasvuolude suhtes kui harilik lutsern $\left[{ }^{4}, 5\right]$ ning talub hästi karjatamist. Tema vormide suur vastupidavus karjatamisele on seletatav harilikust lutsernist erineval arenemisega; viimane teatavasti ei ole karjatamiskindel [?].

Ohukestel rähkmuldadel annab sirplutsern rahuldava saagi; soodsates kasvutingimustes aga annab ta küllalt kõrge heinasaagi ja parema seemnesaagi kui sinine lutsern $\left[{ }^{6}, 8\right]$.

Kohaliku sirplutserni puuduseks on nõrk ädalakasv, lamavad varred, mis raskendavad koristamist, kiire puitumine ja raskused seemne kasvatamisel [5].

Saartel esinev sirplutserni vorm on juurevõrseline. Esimestel kasvuaastatel areneb tal üks peajuur koos suure hulga kõrvaljuurtega, kusjuures osa juuri asetseb mullas madalalt, suundudes paralleelselt mullapinnaga. Mullapinnaga paralleelselt asetsevatel juurtel arenevad 3.-4. kasvuaastal juurepungadest uued sammasjuured, mis mõnikord saavutavad peajuurega võrd- 
sed mõõtmed. Seoses uute sammasjuurte tekkimise ja arenemisega tärkab ka uusi maapealseid võrseid ning lutsernipuhmas laieneb.

- Kohaliku sirplutserni 1-2-aastastel taimedel asub võrsumissõlm (juurekael) $\quad 0,5-2 \mathrm{~cm}$ sügavusel, $20-30$-aastastel taimedel $6-7 \mathrm{~cm}$ sügavusel.

Kohaliku sirplutserni sügisene ja suvine leherosett on lamav. Varred lamavad või tõusvad ning tugevasti hargnenud. Alumised kõrvalharud on peavarrest sageli pikemad, läbilõikelt ümarjaist kuni neljakandilisteni, aluselt on nad rohkem neljakandilised, tumerohelised ning sageli värvunud antotsüaaniga, kogu ulatuses on nad kaetud peente valgete ligisurutud karvakestega. Varreõ̃nsus on täidetud. Varte arv puhmas 20-140, nende pikkus $30-120 \mathrm{~cm}$, läbimõõt aluselt $1-4 \mathrm{~mm}$. Lehisus on hea, lehtede protsent oitsemise algul 45-54.

Sirplutserni lehed on kolmetised, lehekesed talbjad, tumerohelised, kaetud alt ja äärtelt mahasurutud karvakestega, lehekese serv tipupoolses osas $(1 / 5-1 / 4$ ulatuses) selgelt hambuline. Lehevarre alusel paiknevad abilehed on pikad, naaskeljad, $2-3$ hambaga. Oisik lühiovaalne kuni munajas kobar. Oierao pikkus 6-32 mm. Sirplutserni õiekobaras on 11-29 helekollaste kroonlehtedega õit. Emakas ja tolmukad on suletud laevukesse; kui õit muljuda, vabanevad nad sealt ja löövad vastu purje.

Vili on paljuseemneline $(2-10)$ sirbitaoline kuni sirge kaun; seeme kolmnurkjas kuni neerjas, rohekaskollane, 1,8--2,1 mm pikk, 1000 seemne kaal 1,0-1,4 g.

Võrreldes hariliku lutserniga hilineb kohaliku sirplutserni kasvu algus kevadel nädala võrra või rohkem. Ädala kasv on aeglane; põuasel suvel võimaldab sirplutsern vaid ühe niite ja annab vähesel hulgal ädalat. Sademeterikkal suvel võib aga niita kaks korda. Nii andis sirplutsern Eesti Maaviljeluse ja Maaparanduse Teadusliku Uurimise Instituudi Karja katsepunktis sademeterikkal 1953. aastal kahe niite kogusaagina 101,7 ts heina hektarilt, kusjuures teise niite saak (56,0 ts ha-1t) ületas esimese saagi $(45,7$ ts ha-1t).

Sirplutsern algab õitsemist üheaegselt hariliku lutserniga; tavaliselt juuni lõpus või juuli algul, ja õitseb kuni sügiseni, mistõttu kaunte valmimine on ebaühtlane ning osa neist pakatab.

Võrreldes hariliku lutserniga on kohalik sirplutsern talve- ja põuakindlam ning ei kannata kevadiste öökülmade all. Tema kasutuskestus on väga pikk; Saaremaal on säilinud 30-40-aastasi sirplutserni külve.

Sirplutsern eelistab lubjarikkaid muldi, kus $\mathrm{pH}$ on $6,5-7,5$ piirides; happelistel muldadel läheb ta kiiresti heintaimikust välja.

Sirplutsern on kõrge söödaväärtusega ning kõ̃ik loomaliigid söövad teda hästi.

\section{Sirplutserni kasutamine põllumajanduses}

Olemasolevail andmeil on Saaremaal sirplutserni esimesena külvatud Laugu mõisas 1914. aastal (praegu «Uhise Jõu» kolhoos); külv on osalt säilinud praeguseni. Sealt on pärit Leisi asunduse ümbruse kolhoosides ja Karja katsepunktis külvatud sirplutsern, mida siin nimetatakse kohalikuks sirplutserniks. Sirplutsern on olnud võrdlemisi saagikas ja püsiv. Nii näiteks on Orissaare rajooni «Vesse» kolhoosis erineva vanuse ja kasutus viisiga külvid andnud aastast aastasse head saaki. Sirplutserni on siin külvatud katteviljata, õhukesele rähkmullale, mille huumuskihi paksus on $12-15 \mathrm{~cm}$; külvinormiks on olnud $20 \mathrm{~kg}$ seemet hektarile. Kõige vanemad külvid on praeguse «Vesse» kolhoosi maadele tehtud 1936. a. üksiktalupidajate poolt Laugu mõisast toodud seemnega; hilisemates külvides on kasutatud kohapeal kasvatatud seemet. Kuni 1950. aastani kasutati 1936. 
aastal rajatud sirplutsernipõlde vahelduvalt niiteliselt ja karjatamiseks, alates 1950. aastast aga ainult karjatamiseks.

1956. aastal saadi neilt põldudelt 80 ts haljasmassi hektarilt. Rohukamaras esineb siin sirplutserni veel kuni $43 \%$ (tabel 1); haljasmassi saagist moodustab ta aga $65-75 \%$.

Tabel 1

Erineva vanusega sirplutsernipõldude rohukamara botaaniline koostis Orissaare rajooni «Vesse» kolhoosis 1956 . aastal

(vōrseid $\mathrm{m}^{2}$ kohta)

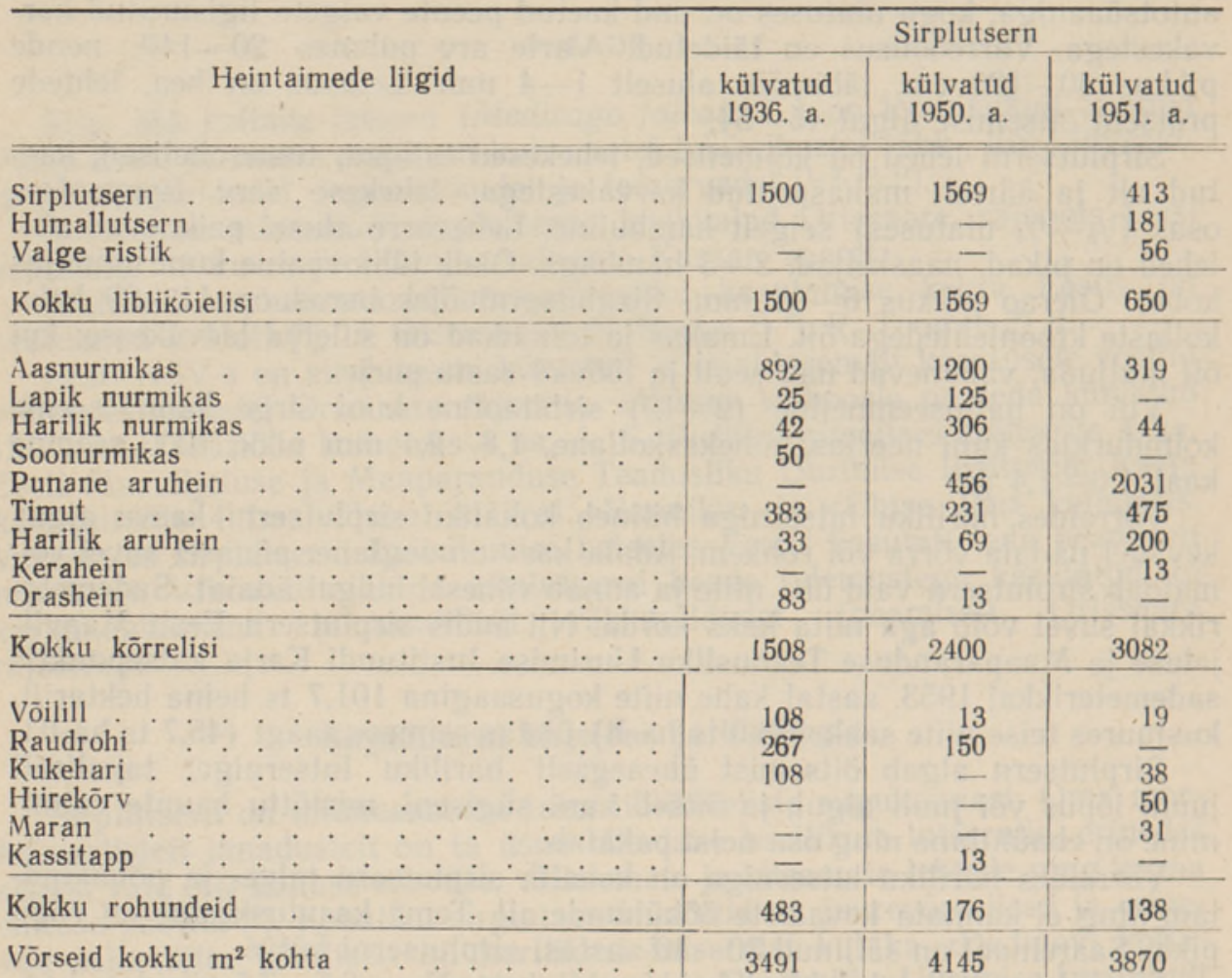

Hiljem on «Vesse» kolhoosis sirplutserni külvatud 1950. ja 1951. aastal. 1950. aastal külvatust kasutati esimene lõikus niiteliselt, ädal - karjatamiseks. 1956. aastal saadi sellelt põllult 22 ts heina ja ädalal karjatades $30-40$ ts haljasmassi hektarilt. 1951. aastal külvatud sirplutserni kasutatakse alates teise kasutusaasta sügisest pidevalt karjatamiseks. Haljasmassi saak oli 1956 . aastal $70-80$ ts hektarilt.

Eeltoodust näeme, et õhukestel rähkmuldadel annab sirplutsern nii niitelisel kasutamisel kui ka karjatades võrdlemisi head saaki ning püsib valitsevalt pikemat laega heintaimikus.

Sirplutserni kasutamisviisi selgitamiseks rajati Eesti Maaviljeluse ja Maaparanduse Teadusliku Uurimise Instituudi Karja katsepunktis 1949. aastal õhukesele rähkmullale, mille huumuskihi tüsedus kõigub $10 \mathrm{~cm}$ piirides, vastav katsepõld. Külv tehti odra alla laialtkülvis, külvinormiga $15 \mathrm{~kg}$ kohaliku päritoluga sirplutserni ja $8 \mathrm{~kg}$ kõrge raiheina seemet hektarile. Pärast külvi põld äestati ja rulliti. 1950. laastal kasutati sirplutserni niiteliselt, saades hektarilt 15 ts heina. 1951. aastal eraldati sirplutserni põllust 2 hektarit karjatamiseks, ülejäänud osa kasutati niiteliselt. Karjatatav pind on jaotatud kaheks hektarisuuruseks kopliks, karjatades neil $4-5$ korda 
suve jooksul. Karjatamisel on lehmadele järgnenud hobused, et tagada koplite ühtlast paljakssöömist. Pärast igakordset karjatamist on koplites laotatud loomade väljaheited; järelniitu on tehtud vastavalt vajadusele.

Kevadel on koplites karjatamist alustatud tavaliselt mai lõpus; viimane karjatamine on toimunud septembri lõpus või oktoobri algul.

Rajamisel ja igal kevadel on katsepõllule antud väetuseks 3 ts superfosfaati ja 2 ts kaaliumkloriidi hektarile.

Niiteliselt kasutatavat sirplutserni on niidetud kaks korda aastas. Esimene niit on toimunud õitsemise algul, teine - septembri või oktoobri algul.

Kuue kasutusaasta (1951-1956) keskmisena saadi aastas niitelisel kasutusel 2850 ja kopliviisilisel karjatamisel 2746 söötühikut hektarilt (tabel 2). Saak on olnud niitelisel kasutusel 104 söötühikut ehk $4 \%$ suurem kui karjatamisel. 1956. aastal saadi niitelisel kasutusel 181 söötühikut ja 1 ts toorproteiini hektarilt rohkem kui karjatamisel.

Tabel 2

Sirplutserni saagid Karja katsepunktis olenevalt kasutusviisist

\begin{tabular}{|c|c|c|c|c|}
\hline \multirow[b]{2}{*}{ Aastad } & \multicolumn{2}{|c|}{ Karjatamisel } & \multicolumn{2}{|c|}{ Niitelisel kasutusel } \\
\hline & $\begin{array}{c}\text { haljasmassi } \\
\text { ts/ha-lt }\end{array}$ & $\begin{array}{l}\text { söötühikuid } \\
\text { ha-lt* }\end{array}$ & $\begin{array}{l}\text { heina } \\
\text { ts/ha-lt }\end{array}$ & $\begin{array}{l}\text { söötühikuid } \\
\text { ha-1t** }\end{array}$ \\
\hline $\begin{array}{l}1951 \\
1952 \\
1953 \\
1954 \\
1955 \\
1956 \\
1951-1956 \text { keskmine }\end{array}$ & $\begin{array}{r}80,0 \\
116,0 \\
162,7 \\
269,1 \\
111,0 \\
118,0 \\
142,8\end{array}$ & $\begin{array}{l}1538 \\
2231 \\
3128 \\
5175 \\
2134 \\
2269 \\
2746\end{array}$ & $\begin{array}{r}27,0 \\
38,0 \\
101,7 \\
99,6 \\
56,0 \\
54,0 \\
62,7\end{array}$ & $\begin{array}{l}1227 \\
1727 \\
4622 \\
4527 \\
2585 \\
2450 \\
2850\end{array}$ \\
\hline
\end{tabular}

* Söötühikusse on arvestatud $5,2 \mathrm{~kg}$ karjamaarohtu.

*** Söötühikusse on arvestatud $2,2 \mathrm{~kg}$ lutsernheina.

Tabel 3

Sirplutserni toorproteiini ja mineraalainete sisaldus Karja katsepunktis 1956. a. olenevalt kasutusviisist (\% kuivainest)

\begin{tabular}{l|c|c|c|c}
\hline \multicolumn{1}{c|}{ Analüüsitud proovid } & $\begin{array}{c}\text { Toorpro- } \\
\text { teiini }\end{array}$ & $\mathrm{P}_{2} \mathrm{O}_{5}$ & $\mathrm{~K}_{2} \mathrm{O}$ & $\mathrm{CaO}$ \\
\hline \hline Esimene karjatamine (8. VI) & & & & \\
$\quad$ Oldproov & 21,00 & 0,60 & 3,35 & 3,63 \\
Lutsern & 30,23 & 0,65 & 3,47 & 4,80 \\
Kōrrelised & 13,13 & 0,48 & 2,88 & 1,61 \\
Teine karjatamine (9. VII) & & & & \\
Oldproov & 19,86 & 0,36 & 2,46 & 5,06 \\
Lutsern & 26,37 & 0,32 & 2,45 & 5,30 \\
Kõrrelised & 14,37 & 0,39 & 3,05 & 2,13 \\
Kolmas karjatamine (21. VIII) & & & & \\
Oldproov & 23,63 & 0,62 & 2,56 & 3,46 \\
Lutsern & 28,00 & 0,40 & 1,58 & 6,08 \\
Körrelised & 17,40 & 0,54 & 3,32 & 2,52 \\
Heinaks niidetult (27. VI) & & & & \\
Oitsemise algul & & & & \\
Oldproov & 16,18 & 0,39 & 2,17 & 4,72 \\
$\quad$ Lutsern & 18,70 & 0,40 & 1,87 & 5,09 \\
Körrelised & 12,82 & 0,36 & 2,29 & 1,25 \\
\end{tabular}


Eeltoodust näeme, et sirplutserni niitelisel kasutamisel on saagid olnud mõnevõrra suuremad kui karjatamisel. Kuna aga söötühiku omahind tuleb niitelisel kasutusel kallim kui karjatamisel, siis vaatamata väikesele enamsaagile on majanduslikult kasulikum kasutada sirplutserni karjatamiseks.

Sirplutsernisaagid tõusid katsetes neljal esimesel kasutusaastal pidevait nii niitelisel kasutusel kui ka karjatamisel. Maksimaalne saak saadi niitelisel kasutusel 1953. aastal (4622 söötühikut) ja karjatamisel 1954. aastal (5175 söötühikut). 1955. a. langes sirplutsernisaak tugeva põua tõttu järsult. Ka 1956. aasta suvi oli sademetevaene. Kahe teineteisele järgnenud sademetevaese suve mõjul kujunes viimastel aastatel sirplutsernisaak tunduvalt madalamaks kui seda oleks võinud eeldada rohukamara seisundi järgi.

Suveperioodi kestel on sirplutserniga karjakoplid andnud põhimise osa saagist (kolme aasta keskmisena 68\%) esimestel karjatamistel mais ja juunis. Haljasmassisaak oli suve teisel poolel madal, eriti 1955. aasta põuasel suvel (tabel 4).

Tabel 4

Sirplutserniga karjakoplite saagi jagunemine karjatamiskuude järgi Karja katsepunktis

\begin{tabular}{|c|c|c|c|c|c|c|c|}
\hline \multirow[b]{2}{*}{ Kuud } & \multicolumn{2}{|c|}{ 1953. a. } & \multicolumn{2}{|c|}{ 1954. a. } & \multicolumn{2}{|c|}{ 1955. a. } & \multirow[b]{2}{*}{$\begin{array}{c}\text { Kolme } \\
\text { aasta } \\
\text { keskmine } \\
\underset{\%}{0}\end{array}$} \\
\hline & $\begin{array}{l}\text { haljas- } \\
\text { massi } \\
\text { ts/ha-lt }\end{array}$ & $\begin{array}{c}\% \\
\text { aasta- } \\
\text { toodan- } \\
\text { gust }\end{array}$ & $\begin{array}{l}\text { haljas- } \\
\text { massi } \\
\text { ts/ha-lt }\end{array}$ & $\begin{array}{c}\% \\
\text { aasta- } \\
\text { toodan- } \\
\text { gust }\end{array}$ & $\begin{array}{l}\text { haljas- } \\
\text { massi } \\
\text { ts/ha-lt }\end{array}$ & $\begin{array}{c}\% \\
\text { aasta- } \\
\text { toodan- } \\
\text { gust }\end{array}$ & \\
\hline $\begin{array}{l}\text { Mai } \\
\text { Juuni } \\
\text { Juuli } \\
\text { August } \\
\text { September }\end{array}$ & $\begin{array}{r}78,3 \\
27,5 \\
20,6 \\
30,3 \\
6,0\end{array}$ & $\begin{array}{r}48 \\
17 \\
13 \\
18 \\
4\end{array}$ & $\begin{array}{l}81,3 \\
55,2 \\
48,9 \\
56,8 \\
26,9\end{array}$ & $\begin{array}{l}30 \\
21 \\
18 \\
21 \\
10\end{array}$ & $\begin{array}{l}33,2 \\
67,1 \\
10,7 \\
- \\
-\end{array}$ & $\begin{array}{l}30 \\
60 \\
10 \\
- \\
-\end{array}$ & $\begin{array}{r}36 \\
32 \\
14 \\
13 \\
5\end{array}$ \\
\hline
\end{tabular}

Nagu katseandmetest selgub, on sirplutserni osatähtsus saagis ja rohukamaras olnud peaaegu sama nii karjatamisel kui ka niitelisel kasutusel (tabel 5 ja 6). Karjatamisel on sirplutserni osatähtsus saagis olnud tunduvalt suurem kesksuvel (tabel 5), mil kõrreliste heintaimede kasv oli põua tõttu pidurdatud. Karjatamisel omab kõrrelistest heintaimedest suurema osatähtsuse heinakamaras laasnurmikas, kuna kõrge raihein, mida sirplutserni kõrval heinaseemnesegusse võeti $8 \mathrm{~kg}$, on väikese karjatamiskindluse tõttu kamarast välja läinud.

Niiteliselt kasutataval alal esinevad sirplutserni kõrval kõrrelistest peamiselt kõrge raihein ja soonurmikas.

Tabel 5

Sirplutserniga heintaimiku botaaniline koosseis erinevate kasutusviiside puhul Karja katsepunktis 1956. a.

(kaalulise botaanilise analüüsi andmeil. \%-des)

\begin{tabular}{|c|c|c|c|c|c|}
\hline $\begin{array}{l}\text { Kasutusviis } \\
\text { taimede rühmad } \\
\end{array}$ & $\begin{array}{l}\text { Esimesel } \\
\text { karjatamisel } \\
(8 . \text { VI })\end{array}$ & $\begin{array}{l}\text { Teisel kar- } \\
\text { jatamisel } \\
\text { (9. VII) }\end{array}$ & $\begin{array}{c}\text { Kolmandal } \\
\text { karjatamisel } \\
(21 . \text { VII })\end{array}$ & $\begin{array}{c}\text { Kolme kar- } \\
\text { jatamise } \\
\text { keskmine }\end{array}$ & $\begin{array}{l}\text { Niitelisel } \\
\text { kasutusel }\end{array}$ \\
\hline $\begin{array}{l}\text { Sirplutsern } \\
\text { Aasnurmikas } \\
\text { Kokku kōrrelisi } \\
\text { Rohundid }\end{array}$ & $\begin{array}{r}49,8 \\
34,0 \\
50,1 \\
0,1\end{array}$ & $\begin{array}{r}88,2 \\
7,2 \\
9,6 \\
2,2\end{array}$ & $\begin{array}{r}43,6 \\
40,0 \\
46,6 \\
9,8\end{array}$ & $\begin{array}{r}60,5 \\
27,0 \\
35,5 \\
4,0\end{array}$ & $\begin{array}{c}64,1 \\
34,6 \\
1,3\end{array}$ \\
\hline
\end{tabular}


Tabel 6

Sirplutserni rohukamara botaaniline koosseis olenevalt kasutusviisist Karja katsepunktis 1956. a. (võrseid $\mathrm{m}^{2}-1$ tk.)

\begin{tabular}{l|c|c}
\hline Heintaimede rühmad & Karjatataval alal & $\begin{array}{c}\text { Niiteliselt kasutataval } \\
\text { alal }\end{array}$ \\
\hline \hline Kokku liblikōielisi heintaimi & 1227 & 1162 \\
Sellest sirplutserni & 1093 & 1137 \\
Kokku kōrrelisi & 2772 & 3055 \\
Sellest aasnurmikat & 2092 & 131 \\
Rohundeid & 165 & 12 \\
Kokku vōrseid $\mathrm{m}^{2}-1$ & 4164 & 4229 \\
\hline
\end{tabular}

\section{Kohaliku sirplutserni saagikus, võrreldes teiste lutserniliikide ja -sortidega}

Kohaliku sirplutserni ja teiste lutserniliikide ja -sortide saagikuse võrdlemiseks rajati Karja katsepunktis 1952. aastal võrdluskatse mitmesuguse päritoluga lutserniliikide ja -sortidega. Katse rajati ühes korduses keskmise

Tabel 7

Lutserniliikide ja-sortide kolme külviviisi keskmised saagid Karja katsepunktis

\begin{tabular}{|c|c|c|c|c|c|c|c|}
\hline \multirow[b]{2}{*}{$\begin{array}{l}\text { Lutserniliigid ja } \\
\text {-sordid }\end{array}$} & \multicolumn{6}{|c|}{ Heinasaak ts/ha-It } & \multirow{2}{*}{$\begin{array}{c}\text { Keskmine } \\
\text { saak } \\
\text { aastas } \\
\% \text {-des }\end{array}$} \\
\hline & 1953. a. & 1954. a. & 1955. a. & 1956. a. & $\begin{array}{l}4 \text { aasta } \\
\text { saak } \\
\text { kokku }\end{array}$ & $\begin{array}{c}\text { keskmine } \\
\text { saak } \\
\text { aastas }\end{array}$ & \\
\hline $\begin{array}{l}\text { \&uusiku sinine» } \\
\text { \&Dedinovi kollane» } \\
\text { Kohalik sirplutsern }\end{array}$ & $\begin{array}{l}93,6 \\
50,2 \\
36,9\end{array}$ & $\begin{array}{r}108,6 \\
59,1 \\
59,6\end{array}$ & $\begin{array}{l}53,6 \\
36,4 \\
36,3\end{array}$ & $\begin{array}{l}48,9 \\
32,1 \\
29,6\end{array}$ & $\begin{array}{l}304,7 \\
177,8 \\
162,4\end{array}$ & $\begin{array}{l}76,2 \\
44,4 \\
40,6\end{array}$ & $\begin{array}{r}100 \\
58 \\
53\end{array}$ \\
\hline
\end{tabular}

sügavusega rähkmullale kolmel külviviisil: katteviljata külv kevadel (28. IV), külv kattevilja (odra) alla kevadel (29. IV) ja katteviljata külv suvel (2. VII). Katses külvati lutsern segus kõrrelistega, kusjuures külvinormiks oli $20 \mathrm{~kg}$ lutserni, $5 \mathrm{~kg}$ kõrge raiheina, $2 \mathrm{~kg}$ timuti ja $2 \mathrm{~kg}$ hariliku aruheina seemet hektarile.

Katses andis nelja esimese kasutusaasta jooksul «Dedinovi kollane» $42 \%$ ja kohalik sirplutsern $47 \%$ madalama keskmise saagi kui «Kuusiku sinine». Seega ei olnud sirplutsernide saagikuses olulist vahet.

Vörreldes hariliku lutserniga on sirplutserni sortide madalam saak tingitud peamiselt nende aeglasest arenemisest esimestel kasvuaastatel; sirplutsern hakkab maksimaalset saaki andma alles 5 . või 6 . kasutusaastal. Seda näitab sirplutserni osatähtsuse iga-aastane tõus lutsernikülvides (joon. 1). Samal ajal kui «Kuusiku sinise» lutserni osatähtsus heinasaagis on esimesel kasutusaastal 56 ja neljandal kasutusaastal $55 \%$, on kohalikul sirplutsernil see vastavalt 18 ja $57 \%$.

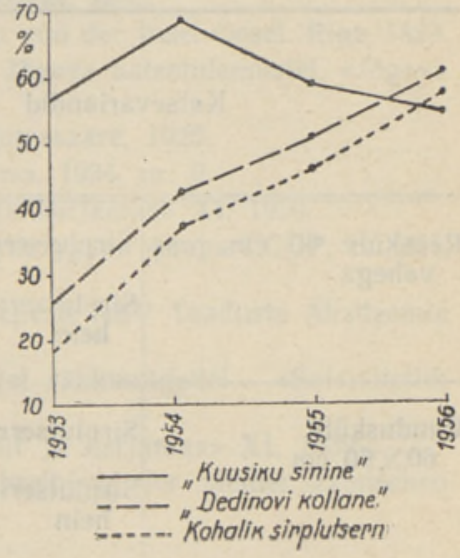

Joon. 1. Lutserni osatähtsus saagis lutserniliikide ja -sortide võrdluskatses Karja katsepunktis. (Kaalulise botaanilise analüüsi andmeil protsentides.) 


\section{Sirplutserni seemnekasvatusest}

Karja katsepunktis on sirplutserni niitelise ja karjatamiseks kasutamise kõrval jäetud ka seemneks. Alastased seemnesaagid on kõikunud 12-185,4 kg vahel hektarilt (tabel 8). Madalad seemnesaagid on tingitud esmajoones taimede tihedast seisust ja vegetatiivosade tugevast kasvust.

Karja katsepunktis on sirplutserni

Tabel 8 seemnesaagi tõstmiseks rakendatud mit-

Sirplutserni keskmised seemnesaagid Karja katsepunktis (kg/ha-lt)

\begin{tabular}{c|c}
\hline Aastad & Seemnesaak \\
\hline \hline 1953 & 17,2 \\
1954 & 22,0 \\
1955 & 12,0 \\
1956 & 185,4
\end{tabular}
mesuguseid agrotehnilisi võtteid. Sel eesmärgil randaaliti 1955 . aasta sügisel (oktoobris) sirplutserni seemnepõldu raske randaaliga.

1956. aastal saadi randaalitud alalt $247,5 \mathrm{~kg}$ seemet hektarilt, seega $33,5 \%$ enam kui randaalimata alalt. Randaalimise tulemusena vähenes heintaimikus kõrreliste heintaimede ja lutserni vegetatiivvõrsete protsent, suurenes aga lutserni generatiivvõrsete arv. Randaalimine on seega üheks lihtsamaks ja odavamaks võtteks lutserni seemnesaagi tõstmisel. Seda on näidanud ka Orissaare rajooni «Edasi», «Hommiku», «Uhise Jõu» jt. kolhooside tulemused hariliku ja sirplutserni vanemate laialtkülvis rajatud seemnepõldude pealtharimisel.

Sirplutserni seemnekasvatamise agrotehnika väljatöötamiseks rajati Karja katsepunktis 1954. rastal katsepỗllud, kasutades järgmisi külviviise: 1) reaskülv $60 \mathrm{~cm}$ reavahega, külvinorm $8 \mathrm{~kg}$ sirplutserni seemet hektarile;

2) ruuduskülv $60 \times 60 \mathrm{~cm}$, külvinorm $3 \mathrm{~kg}$ sirplutserni seemet hektarile;

3) reaskülv $60 \mathrm{~cm}$ reavahega, seemnesegus $70 \%$ lutserni, $30 \%$ kõrget raiheina (arvestatud puhaskülvi normist) ja 4) ruuduskülv $60 \times 60 \mathrm{~cm}$, seemnesegus $70 \%$ lutserni ja $30 \%$ kõrget raiheina.

Kõige paremaid tulemusi andis seemnepõld, kus oli kasutatud ruuduskülvi; siit saadi $77 \%$ võrra suuremat seemnesaaki kui reaskülviga põllult (tabel 9).

Tabel 9

Sirplutserni seemnesaakide olenevus külviviisist Karja katsepunktis

\begin{tabular}{|c|c|c|c|c|c|}
\hline \multirow{2}{*}{\multicolumn{2}{|c|}{ Katsevariandid }} & \multicolumn{2}{|c|}{$\begin{array}{l}\text { Seemnesaak } \\
\mathrm{kg} / \mathrm{ha}-\mathrm{lt}\end{array}$} & \multirow{2}{*}{$\begin{array}{c}\text { Kahe } \\
\text { aasta } \\
\text { saak } \\
\text { kokku } \\
\mathrm{kg} / \mathrm{ha}-1 \mathrm{t}\end{array}$} & \multirow{2}{*}{$\begin{array}{l}\text { Saak } \\
\% \text {-des }\end{array}$} \\
\hline & & 1955. a. & 1956. a. & & \\
\hline $\begin{array}{l}\text { Reaskülv } 60 \mathrm{~cm} \text { rea- } \\
\text { vahega }\end{array}$ & $\begin{array}{l}\text { Sirplutsern } \\
\text { Sirplutsern + kõrge rai- } \\
\text { hein }\end{array}$ & 80,5 & 255,9 & 395,7 & 100 \\
\hline $\begin{array}{l}\text { Ruuduskülv } \\
60 \times 60 \mathrm{~cm}\end{array}$ & $\begin{array}{l}\text { Sirplutsern } \\
\text { Sirplutsern + kõrge rai- } \\
\text { hein }\end{array}$ & 131,0 & 569,4 & 700,4 & 177 \\
\hline
\end{tabular}

Kõrge raiheina segusse võtmisel vähenes seemnesaak, sest kõrrelised oma tugevasti arenenud juurestikuga vähendavad mulla pealmise kihi veevarusid ja koos sellega lutsernile kättesaadavaid toitaineid, mis põhjustab 
sirplutserni õite ja kaunte mahavarisemist ning seemnesaagi langust. Ruuduskülvil on lutserni varte arv pindühiku kohta väiksem, valguse, õhu ja tolmeldajate putukate juurdepääs soodsam; see kõik aitab kaasa seemnesaagi suurenemisele.

Ruuduskülvi paheks on seemnepõllu tunduvalt raskendatud koristamine. Mõlemas suunas harimise tulemusena kõrgenevad pesade kohad, mida mööda lamanduvad lutserni varred põimuvad läbi naaberpesades kasvavate taimede vartega. Niisuguse põllu niitmine masinaga on võimatu, samuti on raskendatud vikatiga niitmine. Seepärast ei saa seda külviviisi soovitada, kuigi ta annab rohkem seemet.

Kolhoosides tuleks sirplutserni seèmnepõllud külvata laialt või kitsarealises külvis, sest siis on võimalik neid koristada niidumasinaga. Laialtkülvis rajatud sirplutserni seemnepõldudelt on Orissaare rajooni kolhoosides tagasihoidliku väetamise korral saadud soodsatel aastatel küllalt kõrgeid seemnesaake. 1956. aastal, mis seemnekasvatuseks oli soodne, landsid laialtkülvis rajatud sirplutserni seemnepõllud Orissaare rajooni «Jüriöö» kolhoosis kuni 7 ts seemet hektarilt, A. S. Puškini nimelises kolhoosis 3 ts ja «Vesse» kolhoosis 2,5 ts.

Uhe agrotehnilise võttena on lutserni seemnesaagi tõstmiseks mitmel pool kasutatud täiendavat tolmeldamist. Karja katsepunktis tehtud vaatlustel on selgunud, et täiendava mehaanilise tolmeldamise tulemusena ei ole sirplutserni seemnesaak märgatavalt tõusnud. Minimaalne on olnud saagi tõus ka mikroväetiste, nagu boori jt. kasutamisel.

Arvestades seniseid kogemusi, tuleb märkida kohalike juurevõrseliste sirplutsernide suurt tähtsust õhukeste rähkmuldade ratsionaalsel kasutamisel. Oma väga pika kasutamiskestuse, suure põuakindluse ja seejuures küllalt kõrge salagikuse tõttu on ta üheks väärtuslikumaks kultuuriks neil muldadel. Sirplutserni kiirel ja ulatuslikul kasutusele võtmisel on oluline tähtsus ratsionaalse söödabaasi väljakujundamisel neis rajoonides, kus õhukeste rähkmuldade osatähtsus on suur.

\section{KIRJANDUS}

1. K J ing e, Joh., Flora von Est-, Liv- und Curland. Reval, 1882.

2. L u c e, Joh. Wilh. Ludw., Topographische Nachrichten von der Insel Oesel. Riga, 1823.

3. Mets, J., Lutserni kasvatamise vōimalustest Eestis Jõgeva katsetulemustel. «Jõgeva Sordikasvanduse Toimetised», nr. 81, 1937.

4. Ot st a we l, H., Lutserne ja selle kasvatamisest. Kuressaare, 1926.

5. Roots i, N., Lutserni kasvatamisest. «Pöllumajandus», 1934, nr. 6.

6. R o otsi, N., Pōldheina kasutamise küsimusi. «Niit ja karjamaa» XI, 1939.

7. С и н ск а я, Е. Н., Люцерна - Medicago L. ЕM. Культурная флора СССР, т. ХIII, в. 1. Ленинград - Москва, 1950.

8. T o o m re, R., Lutserni kasvatamisest Eesti NSV-s. «Eesti NSV Teaduste Akadeemia Toimetised», 1953, nr. 1.

9. To o mre, R., Sirplutsern karjamaataimena ōhukestel rähkmuldadel. «Sotsialistlik Pōllumajandus», 1953, nr. 10.

10. Vi i r a, Joh., Lutserni kasvatamisest Saaremaal. «Niit ja karjamaa» XI, 1939.

11. Wiedemann, F. J. und Weber, E., Beschreibung der phanerogamischen Gewächse Esth-, Liv- und Curlands. Reval, 1852. 


\title{
РАСПРОСТРАНЕНИЕ МЕСТНОИ СЕРПОВИДНОИ ЛЮЩЕРНЫ И ЕЕ СЕЛЬСКО- ХОЗЯИСТВЕННОЕ ИСПОЛЬЗОВАНИЕ НА О. СААРЕМАА
}

\author{
B. Х. Лаур
}

Резюме

Серповидная люцерна (желтая люцерна) распространена в диком виде в северной части Эстонии и на островах. Она является корневищным растением, чем и отличается от других видов люцерны, культивируемых в Әстонии.

В последние годы местную серповидную люцерну начали культивировать и использовать на корма в некоторых колхозах Ориссаареского района (о. Сааремаа) и на находящемся в том же районе опытном пункте «Карья» Научно-исследовательского института земледелия и мелиорации Министерства сельского хозяйства Эстонской ССР.

Первые посевы серповидной люцерны были заложены здесь в 1914 г. и сохранились до настоящего времени, что свидетельствует о ее большой долговечности.

В колхозах района серповидная люцерна используется главным образом под выпас скота без соблюдения правил загонной системы; средний урожай зеленой массы составлял при этом $70-80$ центнеров с гектара.

Первые опыты с местной серповидной люцерной на опытном пункте «Карья» были заложены в 1949 г. на маломощной рихковой почве. За 6 лет средний урожай укосной массы составлял 2856 кормовых единиц и при загонном использовании под выпас 2746 кормовых единиц с гектара. Максимальный урожай получен в годы с наибольшим количеством осадков: в 1953 г. с укосных угодий 4622 и с пастбищ (в 1954 г.) 5175 кормовых единиц с гектара. В засушливые 1955 и 1956 гг. урожай серповидной люцерны значительно снизился.

По данным анализа, проведенного в 1956 г. на опытном пункте «Карья», удельный вес серповидной люцерны в травостое был одинаковым как на укосных угодьях, так и на пастбищах, составляя $30 \%$ от количества всходов на единицу площади.

При сборе урожая удельный вес люцерны составлял при выпасе скота 60,5\% и при скашивании $64,1 \%$.

Содержание сырого протеина в травах пастбищ составляло в 1956 г. (в абсолютно сухом веществе) - 19,86-23,63\%, причем в люцерне, составлявшей часть урожая, $26,37-30,23 \%$. При скашивании на сено содержание сырого протеина составляло (в абсолютно сухом веществе) $16,18 \%$, в том числе только в серповндной люцерне $18,70 \%$.

При сравнительных опытах, проведенных на опытном пункте «Карья», средний урожай первых четырех лет местной серповидной люцерны был на $47 \%$ и Дединовской желтой на $42 \%$ ниже урожая синей люцерны. Низкий урожай местной серповидной люцерны по сравнению с синей люцерной был обусловлен главным образом медленным развитием ее в начальный период вегетации. Так, например, удельный вес обыкновенной люцерны в урожае составлял в первый год $56 \%$ и в четвертый год $55 \%$, местной же серповидной люцерны соответственно $18 \%$ и $57 \%$.

Урожаи семян местной серповидной люцерны на опытном пункте «Карья» составляли, в зависимости от метеорологических условий, 12-185,4 кг с гектара. Осеннее дискование семенников люцерны, засеянных вразброс, повысило урожай семян на $33,5 \%$.

Лучшие урожаи семян люцерны на опытном пункте «Карья» получены с семенников, засеянных квадратным способом $(60 \times 60 \mathrm{~cm})$. Однако при квадратном посеве затруднена машинная уборка семенников, в связи с чем его нельзя рекомендовать к практическому применению. Опыты показали также, что при закладке семенников люцерны совместно со злаковыми урожай семян люцерны снижается.

Наиболее целесообразным методом закладки семенников серповидной люцерны следует считать разбросной или узкорядный посев. Сбор урожая при этом способе значительно облегчается и в благоприятные годы с этих участков, даже при небольшом количестве удобрений, получены хорошие урожаи семян - от 2,5 до 7 центнеров с гектара.

На основе опыта, приобретенного опытным пунктом «Қарья» и колхозами Ориссаареского района, можно утверждать, что ценными свойствами местной серповидной люцерны являются ее долговечность, устойчивость при стравливании скотом и возможность получать удовлетворительные урожаи на маломощных рихковых почвах, где выращипание других сельскохозяйственных культур затруднительно. 


\title{
VERBREITUNG UND LANDWIRTSCHAFTLICHE VERWENDUNG DER EINHEI- MISCHEN SICHELLUZERNE AUF DER INSEL SAAREMAA
}

\author{
W. Laur \\ Zusammenfassung
}

Die in Nordestland und auf den estnischen Inseln naturwüchsig verbreitete Sichelluzerne ist eine wurzelspriessende Pflanze und unterscheidet sich in dieser Hinsicht von allen anderen in Estland angebauten Luzernensorten.

In den letzten Jahren ist die einheimische Sichelluzerne in einigen Kollektivwirtschaften des Bezirkes Orissaare ausgesät worden, gleichwie in der Versuchsstation Karja (Bezirk Orissaare) des Estnischen Instituts für wissenschaftliche Eriorschung der Agrikultur und Melioration.

Die erstmalige Aussaat der genannten Pflanze erfolgte im Bezirk Orissaare im Jahre 1914. Ihr Fortbestehen auf den betreffenden. Flächen bezeugt ihre ausserordentliche Dauerhaftigkeit.

In den Kollektivwirtschaften wird die einheimische Sichelluzerne auf armen Gesteinböden gesät, die vornehmlich als Weideland benutzt werden, wobei der Ertrag 70-80 Doppelzentner Grünmasse pro ha beträgt.

In der Versuchsstation Karja lieferte die einheimische Sichelluzerne auí armen Gesteinböden als Durchschnitt von sechs Jahren 2856 Futtereinheiten beim Gebrauch als Heuschlag und 2746 Futtereinheiten beim Gebrauch als Weide.

Beim Vergleich der verschiedenen Sorten der Luzerne in der Versuchsstation Karja ergab die einheimische Sichelluzerne in den vier ersten Jahren im Durchschnitt einen um $47 \%$ geringeren Ertrag als die Blauluzerne.

Der geringere Ertrag erklärt sich durch die langsamere Entwicklung dieser Pflanze in ihrem ersten Stadium.

Zur Samenzucht der Sichelluzerne eignet sich am besten breitere oder schmälere Streifensaat. So angelegte Felder sind leicht zu bebauen und liefern gute Samenerträge: in guten Jahren 2,5-7 Doppelzentner pro ha.

Die einheimische Sichelluzerne ist im allgemeinen eine wertvolle landwirtschaftliche Kultur, da sie überaus dauerhaft und beständig ist und auf ärmeren Gesteinböden, wo der Anbau anderer Kulturen schlecint gelingt, noch hinreichende Erträge gibt.

\section{Institut für Ackerbau und Melioration} der Estnischen SSR

Eingegangen am 17. Juni 1957 